\title{
STUDY OF THE MENSTRUAL CYCLE IN FOREIGN FIRST-YEAR STUDENTS OF RUDN UNIVERSITY
}

\section{Shushanik Arutuynyan (D), Elina Kitaeva (D), Elena Lim (D), Artem Fedorov (D), Ekaterina Bushueva $\mathbb{D}^{\mathrm{D}}$, Zinfira Kaitova ${ }^{\bowtie}(\mathbb{D}$,}

I.D. Kirpatovsky Department of Operative Surgery and Clinical Anatomy, Medical Institute, RUDN University

$\triangle$ zinfira_kaitova@mail.ru tion to another sociocultural environment. All this actualizes the problem of social adaptation of foreign students (2).

According to the observations of many gynecologists, stress and psycho-emotional experiences are often reflected in the menstrual cycle in the form of various disorders. Moreover, there are changes in the hormonal system of foreign students. It is no secret that psycho-emotional fluctuations can contribute to the launch of new diseases in the female body. According to the gynecologist Iev Daise, the risk group includes young active and practically healthy girls, in whom the body reacts to a large physical and psychoemotional load, and possibly to excessive demands on themselves (3). Thus, a relationship was established between the stress state and hormonal imbalance.

\section{PURPOSE}

To study changes in the menstrual cycle in foreign students of the first year of study at the university.

\section{OB JEC T IVES}

Identify changes in food culture; identify weight changes and study the psycho-emotional state of students.

\section{MATERIALS AND METHODS}

To solve the tasks, we have developed a special questionnaire, consisting of 15 points, including such questions as age? Weight? The beginning of the menstrual cycle? Which country? Having sex, etc. The questions are designed in such a way that it is possible to identify the pattern of change in the menstrual cycle in stressful situations or to refute the relationship between them.

\section{RESULTS AND DISCUSSIONS.}

The survey involved 43 students, 13 of them are studying at the preparatory faculty, and 30 in the first year. The distribution of female students by faculty, we presented in Fig. 1.

The study involved foreign students in their first year of residence in Russia. Survey results showed that 21 of one girl's weight increased from 6 to $17 \mathrm{~kg}$, and 17 students lost weight from 4 to $20 \mathrm{~kg}$. Only 5 girls showed a slight change in weight by an average of $\pm 1.2 \mathrm{~kg}$. It should be noted that one foreign student of the Faculty of Economics (Colombia) lost $20 \mathrm{~kg}$ other culture and are biased towards it, which cannot but affect the length and complexity of their adapta- 


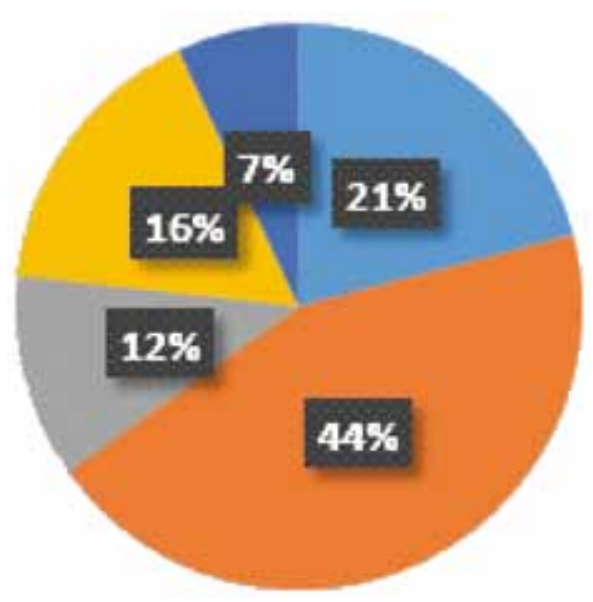

Fig. 1.

in weight, while a student of the Faculty of Medicine (North Caucasus) showed an increase in weight of up to $17 \mathrm{~kg}$ over 1 year. Also, according to the results of the survey, we found that 18 girls had a complete cessation of menstruation from 2 to 6 months. It was revealed that in 23 girls menstruation became more plentiful, painful and prolonged. Of all the examined, only 2 girls had no menstrual irregularities. Perhaps this is due to the fact that students took birth control drugs 1.5 years before moving to Russia. It turned out that the smallest violations of the menstrual cycle in students from neighboring countries compared with students from Latin America.

\section{RECOMMENDATIONS}

1. It is necessary to first study the climatic and social characteristics of the country of entry in order to reduce the negative effects on the body of the educational and psycho-emotional load.

2. Before coming to colder countries, it is advisable to take medications to maintain immunity.

3. Parents conduct educational work with children on the food ethics of the child.

\section{REFERENCES}

1. Astafieva, L. S. (2010). Features of the adaptation of foreign students at the preparatory faculty. Bulletin of the Peoples' Friendship University of Russia. Series: Psychology and Pedagogy, (4).

2. Kapezina, T. T. (2014). Problems of teaching foreign students in a Russian university. The science. Society. State, (1).

3. Islakaeva, G. R. (2016). Educational interregional migration: causes and socio-economic consequences. The standard of living of the population of the regions of Russia, (3 (201)).

4. Mareev P.V., Somitov S.M. Features of menstrual cycle of students from Asia,Africa,Latin America in Moscow //'Scietifical bases of students human:-M., 1987.- C. 117-119. 